\title{
Fibrogenesis Markers and Hepatic Histopathology : What is the Role?
}

\author{
Ibrahim Mohamed Ibrahim \\ Tropical Medicine Department, Faculty of Medicine, Zagazig University, Egypt \\ See article pages:4-11
}

\section{Background}

$\mathrm{HCV}$ infection has an estimated prevalence of $3 \%$ around the world[1], and Egypt is among the highest prevalence [2]. Asymptomatic HCV patients are underrepresented.Unfortunately, many persons with HCV infection are asymptomatic[3]. Many asymptomatic seropositive donors have clinically significant liver disease[4]. The progression to severe fibrosis and occurrence of HCC were reported [1, 2]. Patients with normal enzymes may have definite chances of chronic hepatitis on histological examination [6].

Percutaneous liver biopsy, is the gold standard for grading and staging liver diseases [7], but it is invasive, has limitations [8], and asymptomatic patientsmay not accept.

The matrix metalloproteinases (MMPs), and their inhibitors are groups of proteins involved in controlling matrix degradation. Therefore, it seems that imbalance between MMPs and TIMPs affects rate of fibrosis progression, and their estimation was correlated with the stage of fibrosis [9].

Aspartate aminotransferase to platelet ratio (APRI Score) was also proved useful to stage liver fibrosis[10].It is an easy and validated predictor of hepatic fibrosis in chronic hepatitis C [11].

Non invasive diagnosis of liver fibrosis and cirrhosis in chronic hepatitis $\mathrm{C}$, is required in pre-treatment and follow up [12].

\section{Summary of paper}

The paper entitled " Can fibrogenesis markers reflect early hepatic histopathology in chronic hepatitis C?" published in this issue of the AfroEgyptian journal of infectious and Endemic Diseases by Abou El-Azm et al., aimed at evaluating individual and combined non invasive indicators of fibrogenesis (MMP-2, T1MP1 and
APRI score) to assess early hepatic histopathology, and developing cirrhosis in chronic HCV patients with and without symptoms. The authors enrolled 344 patients (Group I:129 asymptomatic chronic-HCV, Group II: 135 with symptoms and Group III: 80 patients with compensated HCV-related cirrhosis). For each patient, APRI-Score was evaluated. Quantitative immunoassay measured serum MMP-2 and TIMP-1. Guided liver biopsy for histopathology staging and grading was done. The results imply that combination of markers raised the sensitivity, specificity and correlations. It could reflect early hepatic histopathology, developing cirrhosis and potentially could replace liver biopsies in pre-treatment and follow up of chronic HCV.

\section{Comment on the study}

The current study showed a significant correlation of AST with the stage of fibrosis in the studied patients. This finding is consistent with the results mentioned that liver fibrosis severity and subsequent cirrhosis were correlated with high AST levels [13].

The current study showed that platelets decreased significantly in severe fibrosis or cirrhosis and these results are in agreement with previous results[14].Decreased platelet count was the earliest indicator of cirrhosis [15].

As regard to direct serum fibrogenesis markers which reflect extracellular matrix turnover, MMP-2 \& TIMP-1were measured and correlated to the stage of fibrosis in liver biopsy.There was a significant positive correlation between serum MMP-2 and serum TIMP-1 and the stage of fibrosis. These results are in accordance with the results of Abdel-Samea et al. [14].

APRI score was reported to have correlations with the stages of histological fibrosis [16], in agreement with the present results .While Khairy $\mathrm{M}$ et al, showed that APRI score had moderate degree of accuracy [10].Ma et al. considered it 
as a tool with limited expense, widespread availability, a promising noninvasive alternative to liver biopsy for detecting hepatic fibrosis and treatment response in patients with chronic hepatitis C [17].

Although the outcome of non-invasive markers in different studies is not the same but multiplicity of markers can give more accuracy. The combined indicators of fibrosis: TIMP-1, MMP-2 and APRI score in the current study showed a higher sensitivity, specificity, and strong correlations with histopathology staging of liver fibrosis.

\section{Recommendations:}

Serum markers of hepatic fibrosis are to replace liver biopsy - especially in the presence of obstacles - in assessment of patients with $\mathrm{HCV}$ related liver disease and in follow up of these patients post-treatment.

Further serum markers of liver fibrosis are to be determined individually or in combination to replace liver biopsy. These markers include procollagen type III N-terminal peptide (PIIINP) [18], procollagen type I N-terminal peptide (PINP) [19], type IV collagen [20], procollagenV C-terminal peptide (PVCP) [21], hyaluronic acid [22], matrix metalloproteinase 1 (MMP 1) and matrix metalloproteinase 9 (MMP 9) [23].

\section{References}

1. Reggiardo MV, Fay F, Tanno M, GarcíaCamacho G, Bottaso O, Ferretti S et al, Natural history of hepatitis $\mathrm{C}$ virus infection in a cohort of asymptomatic post-transfused subjects. Ann Hepatol. 2012;11(5):658-66

2. El-Zayadi AR, Abaz HF, Shawjy S, Mohamed MK, Selim OE, Badran HM. Prevalence and epidemiological features of hepatocellular carcinoma in Egypt: A single centre experience. Hepatol. Res. 2001; 19:170-179.

3. Persico M, Palmentieri B, Coppola L, Di Giacomo Russo G, De Marino F, De Sio I, et al. Occurrence of HCC in asymptomaticHCVrelated chronic hepatitis. Dig Dis Sci. 2002;47(11):2407-10.

4. Puoti C, Guarisco R, Spilabotti L. Should we treat HCV carriers with normal ALT levels? The '5Ws' dilemma. J Viral Hepat. 2012;19(4):22935.
5. Méndez-Sánchez N, Ponciano-Rodriguez G, Chávez-Tapia NC, Motola-Kuba D, AlmedaValdes P, Sánchez-Lara K et al. Prevalence of hepatitis $\mathrm{C}$ infection in a population of asymptomatic people in a checkup unit in Mexico city. Dig Dis Sci. 2005;50(4):733-7.

6. Neelima Jain, BK Tripathy, B Gupta. Hepatitis Infection: Natural History and Long Term Complications. Journal, Indian Academy of Clinical Medicine. 2000, 5: 38-41.

7. Regev A, Berho M, Jeffers L, Milikowski C, Molina EG, Pyrsopoulos NT et al. Sampling error and intraobserver variation in liver biopsy in patients with chronic HCV infection. Am. J. Gastroenterol. 2002; 97:2614-2618.

8. Castera L, Denis J, Babany G, Roudot-Thoraval F. Evolving practices of noninvasive markers of liver fibrosis in patients with chronic $\mathrm{HCV}$ in France: Time for new guidelines? J. Hepatol. 2007; 46(3):529-530.

9. Boeker KH, Habercom CI, Michels D, Flemming $\mathrm{P}$, Manns MP, Lichtinghagen R. Diagnostic potential of circulating TIMP1 \& 2 as markers of hepatic fibrosis in $\mathrm{HCV}$ patients. Clin.Chim. Acta. 2002; 316:71-81.

10. Khairy M, Abdel-Rahman M, El-Raziky M, ElAkel W, Zayed N, Khatab H, et al. Non-invasive prediction of hepatic fibrosis in patients with chronic HCV based on the routine pre-treatment workup. Hepat Mon. 2012;12(11):e6718.

11. Snyder N, Gajula L, Xiao SY, Grady J, Luxon B, Lau DT, et al. APRI: an easy and validated predictor of hepatic fibrosis in chronic hepatitis C. J Clin Gastroenterol. 2006;40(6):535-42.

12. Attallah AM, El-Far M, Omran MM, Farid K, Albannan MS, El-Dosoky I. Noninvasive Diagnosis of Liver Fibrosis and Cirrhosis in Chronic Hepatitis C Patients. J Clin Lab Anal. 2013;27(2):121-9.

13. Moustafa HM, Fathy A, Gadalla HE. Noninvasive assessment of hepatic fibrosis in chronic $\mathrm{HCV}$ patients. Liver International. 2006; 26(1):33.

14. Abdel-Samea ER, Abdel-Gawad SS and Ali MA. Evaluation Of Serum Hyaluronic Acid And Matrix Metaloproteinase-2 As Non Invasive Markers Of Hepatic Fibrosis. Life Science Journal. 2011; 8(2):19-25.

15. Karasu Z, Tekin F, Ersoz G, Batur Y, Ilter T, Akarca US. Liverfibrosis is associated with decreased peripheral platelet count in patients with chronic hepatitis B and C. Dig Dis Sci. 2007 Jun;52(6):1535-9. Epub 2007 Apr 27. 
16. Jin W, Lin Z, Xin Y, Jiang X, Dong Q, Xuan S. Diagnostic accuracy of the aspartate aminotransferase-to-platelet ratio index for the prediction of hepatitis B-related fibrosis: a leading meta-analysis. BMC Gastroenterol. 2012 $14 ; 12: 14$.

17. Ma J, Jiang Y, Gong G. Evaluation of seven noninvasive models in staging liver fibrosis in patients with chronic hepatitis B virus infection. Eur J Gastroenterol Hepatol. 2013;25(4):428-34.

18. Collazos J, Diaz F. Role of the measurement of serum procollagen type III N-terminal peptide in the evaluation of liver diseases. Clin Chim Acta. 1994;227(1-2):37-43.

19. Veidal SS, Vassiliadis E, Bay-Jensen AC, Tougas G, Vainer B, Karsdal MA. Procollagen type I Nterminal propeptide (PINP) is a marker for fibrogene $\neg$ sis in bile duct ligation-induced fibrosis in rats. Fibrogenesis Tissue Repair. 2010;3(1):5.

20. Hirayama C, Suzuki H, Takada A, Fujisawa K, Tanikawa K, Igarashi S. Serum type IV collagen in various liver diseases in comparison with serum 7S collagen, laminin, and type III procollagen peptide. $J$ Gastroenterol. 1996;31(2):242-8.

21. Vassiliadis E, Veidal SS, Simonsen H, Larsen DV,Vainer B,Chen $X$, et al. Immunological detection of the type $\mathrm{V}$ collagen propeptide fragment, PVCP-1230, in connective tissue remodeling associated with liver fibrosis. Biomarkers. 2011; 16(5):426-33.

22. McHutchison JG, Blatt LM, De Medina M, Craig JR, Conrad A, Schiff ER, et al. Measurement of serum hyaluronic acid in patients with chronic hepatitis $\mathrm{C}$ and its relationship to liver histology. Consensus Interferon Study Group. J Gastroenterol Hepatol. 2000;15(8):945-51.

23. Leroy V, Monier F, Bottari S, Trocme C, Sturm $\mathrm{N}$, Hilleret $\mathrm{MN}$, et al. Circulating matrix metalloproteinases 1, 2, 9 and their inhibitors TIMP-1 and TIMP-2 as serum markers of liver fibrosis in patients with chronic hepatitis $\mathrm{C}$ : comparison with PIIINP and hyaluronic acid. Am J Gastroenterol. 2004;99(2):271-9. 